\title{
Studies on Pumice Lightweight Aggregate Concrete with Quarry Dust Using Mathematical Modeling Aid of ACO Techniques
}

\author{
J. Rex ${ }^{1}$ and B. Kameshwari ${ }^{2}$ \\ ${ }^{1}$ Department of Civil Engineering, SSM Institute of Engineering and Technology, Dindigul, Tamil Nadu 624 002, India \\ ${ }^{2}$ Department of Civil Engineering, RVS College of Engineering and Technology, Dindigul, Tamil Nadu 624 005, India \\ Correspondence should be addressed to J. Rex; rexj0586@gmail.com
}

Received 1 August 2015; Revised 20 October 2015; Accepted 21 October 2015

Academic Editor: Belal F. Yousif

Copyright (C) 2016 J. Rex and B. Kameshwari. This is an open access article distributed under the Creative Commons Attribution License, which permits unrestricted use, distribution, and reproduction in any medium, provided the original work is properly cited.

\begin{abstract}
The lightweight aggregate is an aggregate that weighs less than the usual rock aggregate and the quarry dust is a rock particle used in the concrete for the experimentation. The significant intention of the proposed technique is to frame a mathematical modeling with the aid of the optimization techniques. The mathematical modeling is done by minimizing the cost and time consumed in the case of extension of the real time experiment. The proposed mathematical modeling is utilized to predict four output parameters such as compressive strength (Mpa), split tensile strength (Mpa), flexural strength (Mpa), and deflection (in mm). Here, the modeling is carried out with three different optimization techniques like genetic algorithm (GA), particle swarm optimization (PSO), and ant colony optimization (ACO) with $80 \%$ of data from experiment utilized for the training and the remaining $20 \%$ for the validation. Finally, while testing, the error value is minimized and the performance obtained in the ACO for the parameters such as compressive strength, split tensile strength, flexural strength, and deflection is $91 \%, 98 \%, 87 \%$, and $94 \%$ of predicted values, respectively, in the mathematical modeling.
\end{abstract}

\section{Introduction}

The aim of the pumice lightweight concrete is to add the quarry dust with the partial replacement of sand for the perfection of strength and the minimization of the cost and time. The High Performance Concrete may be aptly described as that unique brand of concrete, which meets with the distinctive efficiency and reliability constraints that are not capable of habitual estimation usually by employing the traditional materials and the conventional mixing, placing, and curing procedures. The concrete is one of the widely used construction materials which generally toe the line of the conventional bathtub hazard rate function curve [1]. The concrete predominantly boasts of superior compressive strength which is boosted by several qualities like elevated abrasion resistance, stiffness, minimal permeability, superior durability, greater early strength gain, and reduced cost per unit load [2]. The Ordinary Portland Cement (OPC), in fact, is a noteworthy material in the creation of concrete which generally functions as its binder to combine all the collected materials. It is pertinent to note that the OPC invariably requires the burning of huge amount of fuel and decay of limestone [3]. In this regard, the lightweight concrete is extensively employed in place of the usual concrete in view of a large number of improved qualities. The most current vantage point of the lightweight concrete is its unique diminished structural dead weight. The dip in the dead weight goes a long way in the diminution in the building expenditure [4]. The employment of the lightweight aggregates (LWA) in concrete offers a multitude of constructive features. The lowdensity of the concrete enjoyed by the lightweight aggregates normally paves the way for the cutback in the dead load of edifices, footings size and dimensions of columns, slabs, and beams [5]. The tensile strength of a model concrete habitually exceeds that of the prototype concrete. Hence, it is all the more essential to be aware of the tensile qualities of the model concrete in the whole modeling task [6]. With a view to augmenting the fracture resistance of the cementitious materials, fibers are recurrently supplemented, which leads to the formation of a composite material compressive strength 
and tensile strength. The compressive strength is individual for the structural applications while the flexural strength is specific for the pavement applications [7]. The fines having less than 150-micron dimension are segregated from the unprocessed crusher dust and the crusher dust devoid of the micro fines is effectively utilized for the overall substitution of sand in masonry and experimented for the fundamental compressive strength [8]. The impact of the crushed stone dust as the fine sand leads to the enhancement in the flexural strength in relation to the concrete with the natural sand and the value goes southward as the percentage of the crusher dust goes upward [9]. In this connection the quarry dust has been kick-started as a viable substitute for the river sand which amazingly adds on additional advantages to the concrete. It is everybody's knowledge that the quarry dust reinforces the strength of the concrete as against the concrete generated out of an equivalent quantity of the river sand, though it paves the way for diminution in the workability of the concrete [10]. In an associated expansion, sizeable quantities of the quarry dust are parked in plenty in the region of caliber in the crushed rock sites. The quarry dust is recognized as the highly functional filler in the bituminous concrete [11]. In the highways construction, it is a common procedure to deploy the quarry fines to steady the lateritic materials employed in the road pavements. However, it is unfortunate that the relative benefit is not found to be entirely exploited in the building of structural elements in the edifices and corresponding structures [12]. The most cost-conscious and the simplest method to achieve a viable alternative for the natural sand is attained from the limestone quarries, the lateritic sand, and the crushing natural stone quarries which is called the manufactured sand [13]. Several investigations were carried out on the cubes and beams to assess the compressive, flexural strengths of the concrete made of the Quarry Rock Dust for three diverse proportions and five dissimilar techniques. Durability tests were carried out for the concrete with the Quarry Rock Dust and analyzed and contrasted with the traditional concrete [14]. In view of the fact that their properties are more or less the same as that of the sand, the marble sludge powder and the quarry dust are effectively employed as fine aggregate in the cement concrete [15]. In this regard, the Ordinary Portland Cement (OPC) is somewhat substituted by fly ash, bottom ash, fine aggregate, coarse aggregate, and Light Expanded Clay Aggregate (LECA) by weights of 5\%, 10\%, 15\%, 20\%, $25 \%, 30 \%$, and $35 \%$, respectively. The mathematical modeling based forecast, in turn, is performed with the active support of the optimization method which is capable of effectively evaluating the compressive strength, the split tensile strength, and the flexural strength with the aid of the recognized input values. The quality of the paper is the strength of pumice lightweight concrete. With partial replacement of the sand with the quarry dust the time and cost are minimized [16].

\section{Literature Review}

In 2012 Sivakumar and Gomathi [17] got name and fame for projecting the fly ash as one of the godsend gifts which can be used as both supplementary cementitious material and lightweight aggregate. The artificially generated lightweight aggregates were obtained from the industrial byproducts like the fly ash, bottom ash, silica fume, blast furnace slag, rice husk, slag or sludge waste or palm oil shell, shale, slate, and clay. The advent of the modern era witnessed with curious eyes the ever-rocking usage of the cost-conscious building materials triggered by the amazing augmentation in the requirement for the lightweight concrete for a host of applications. Of late, the inclusion of the artificial aggregates paved the way for a realistic cutback in the building outlays and has become the cynosure of attraction in view of its shining quality equivalent to those of the traditional aggregates.

In 2013 Kabir et al. [18] amazingly advocated the potential utilization of the early-day compressive strength outcomes to forecast the characteristic strength of the standard weight concrete which was the subject matter of research. An easy mathematical model equipped with the acumen of forecasting the compressive strength of concrete at any age was elegantly launched for both the stone and the local aggregate concrete. The data deployed in this exploration were gathered from certain earlier researches and modern investigational endeavors. The evaluations performed by means of the innovative technique employing diverse data effectively illustrated convincing forecast of the concrete strength at various ages such as 7, 14, and 28 days with incredible excellence.

In 2013 Afify and Soliman [19] had their glorious days when they valiantly launched the lightweight aggregates and the chemical admixtures which cast a very significant part in the manufacture of the lightweight concrete. It was heartening that the innovative artificial coarse aggregate was in the pipeline, riveting the eager eyes of the enthusiastic experimenter, and it was well-geared to be deployed in the production of the lightweight concrete. The captioned investigation was spearheaded with an eye on ascertaining the viability of the lightweight aggregate type commercially offered in the domain of the concrete industry in Egypt. The configuration performance of the tested beams and slabs was subjected to deep experimentation with special focus on their deflections, longitudinal strain and cracking against the backdrop of various stages of loading in addition to the final loads and modes of breakdown.

In 2013 Devi [20] vividly explained the corrosion as the fundamental durability issue triggering the corrosion of the concrete structures. Thus, the underlying aim behind the investigation is to evaluate the strength and corrosion resisting the qualities of concrete having the quarry dust as the fine aggregate together with calcium nitrite as the corrosion inhibiting admixture at the dosage of $1 \%, 2 \%, 3 \%$, and $4 \%$ in terms of weight of the cement. Experimentations were performed to ascertain the strength, the water absorption capacity, and the durability and the outcomes were analyzed and contrasted with the natural sand concrete. The corrosion resistance efficiency was evaluated by means of the impressed voltage method, the rapid chloride permeability test, and the gravimetric weight loss technique. The cheering outcomes proclaimed the efficacy of the quarry dust as the most appropriate alternative for the river sand in the concrete which is competent to perk up the strength of the concrete, 
and especially with the addition of the inhibitor it is found to offer very effective resistance against the corrosion.

In 2013 Nagpal et al. [21] were wise enough to advocate the appropriateness of the crushed stone dust waste as the fine aggregate for the concrete which was analyzed and its fundamental traits contrasted with those of the traditional concrete. Two vital mixes were chosen for the natural sand to attain the M25 and M30 grade concrete. The equivalent mixes were attained by substituting the natural sand with the stone dust in part and also completely. The fascinating outcomes proved without any iota of doubt that the crushed stone dust waste had the quality of being employed extensively and effectually as a substitute for the natural sand in the concrete. In the test investigations regarding the strength qualities of the concrete using the crushed stone dust as the fine aggregate it was unequivocally established that the enhancement in the compressive strength, the flexural strength, and the tensile strength of the concrete had been awesome and amazing.

In 2014 Subbulakshmi and Vidivelli [22] convincingly spelt out the fact that the High Performance Concrete was capable of accomplishing incredibly higher performance from the concrete as against the one achieved by the routing concrete. The ambit of the current investigation was elongated to cover the research regarding the impact of the quarry dust towards the efficiency in accomplishment of the High Performance Concrete. An earnest endeavor was made to keep a keen eye on the mechanical qualities of High Performance Concrete created with quarry dust material. The strength qualities like the compressive strength and flexural strength were subjected to experimentation to ascertain the optimum substitution of the quarry dust. The feat of the concrete ratio and quarry dust substitution level on the compressive strength of the quarry dust concrete also became the subject matter of intensive investigation.

\section{Proposed Methodology}

The technique effectively employed forecast the objective function by means of the mighty mathematical modeling. The training and testing technique is deployed to ascertain the objective function of the mathematical model. The coarse aggregate (CA), fine aggregate (FA), cement, water, silica fume (SF), superplasticizer (SP), quarry dust (QD), load $(\mathrm{KN})$, and ultimate load $(\mathrm{KN})$ are the various significant parameters that are made use of to train the mathematical model by exploiting $80 \%$ test database and the residual $20 \%$ finds itself grossly engaged in authenticating the mathematical model. Once the authentication is over, the mathematical model is well set to pursue its paramount purpose of ushering in the objective function of the concrete mixing task. Thereafter, the optimization algorithm is entrusted with the indubitable task of predicting various parameters such as optimal compressive strength (Mpa), split tensile strength (Mpa), flexural strength (Mpa), and deflection (in $\mathrm{mm}$ ). With this end in view, a feast of diverse optimization algorithms are used to evaluate the optimal solutions and the most prominent among them are kingpin genetic algorithm (GA), particle swarm optimization (PSO), ant colony optimization
TABLE 1: Properties of aggregate.

\begin{tabular}{lcc}
\hline Sl. number & Chemical contents & Percentage (\%) \\
\hline 1 & $\mathrm{CaO}$ & 4.6 \\
2 & $\mathrm{SiO}_{2}$ & 59.2 \\
3 & $\mathrm{Al}_{2} \mathrm{O}_{3}$ & 16.6 \\
4 & $\mathrm{Fe}_{2} \mathrm{O}_{3}$ & 4.80 \\
5 & $\mathrm{MgO}$ & 1.8 \\
6 & $\mathrm{SO}_{3}$ & 0.40 \\
7 & $\mathrm{~K}_{2} \mathrm{O}$ & 5.40 \\
8 & $\mathrm{Na}_{2} \mathrm{O}$ & 5.60 \\
9 & Loss on ignition & 1.60 \\
\hline
\end{tabular}

(ACO), and artificial bee colony (ABC) optimization algorithm. The related optimization algorithms invariably resort to their own unique optimization procedures for bringing to limelight the optimal value. In the optimization procedure, at the out the constraints such as the minimum cost and time reduction are assigned. The objective functions are effectively evaluated by means of the optimal solutions like coarse aggregate (CA), fine aggregate (FA), cement, water, silica fume (SF), superplasticizer (SP), quarry dust (QD), load (KN), and ultimate load $(\mathrm{KN})$. In fact the characteristic of the ant colony optimization (ACO) algorithm procedure is mainly assigned the paramount task of ascertaining the optimal solutions like compressive strength (Mpa), split tensile strength (Mpa), flexural strength (Mpa), and deflection (in $\mathrm{mm}$ ) which pave the way for the incredible scaling down of the financial outlays together with fabulous decrease in the time-frame.

3.1. Materials Used for Experimental Work. In the experimental work, the Ordinary Portland Cement is used. Normal river sand is used as fine aggregate with specific gravity of 2.82 and the course aggregate used is the pumice lightweight aggregate of size $16 \mathrm{~mm}$. The mix design is based on the ACI method. The chemical properties of the pumice aggregate are presented in Table 1.

3.2. Mix Proportion and Laboratory Testing Program. Eight types of concrete mixtures with different proportions of lightweight aggregate and quarry dust are offered. In addition to the above mixture concrete is mixed with silica fume in replacement of cement up to $10 \%$ and chemical admixture of SP430 is added at $2 \%$ to cement weight (Table 2).

3.3. Cube Compressive Strength. The different mixes were moulded in cube of size $150 \times 150 \times 150 \mathrm{~mm}$ for testing the compressive strength. Before moulding, the mould is thoroughly cleaned using a waste cloth and properly oiled along its faces. Then the concrete was poured into the mould, compacted, and cured for 7 days and 28 days. After curing the cube is dried and tested in CTM and the compressive strength is found and listed in Table 3. 
TABLE 2: Mixing proportions.

\begin{tabular}{lcccl}
\hline Sl. number & Mix type & Pumice aggregate (\%) & Quarry dust (\%) & Admixtures \\
\hline 1 & M1 & 100 & 0 & \\
2 & M2 & 90 & 10 & \\
3 & M3 & 80 & 20 & 10\% of cement is replaced with silica \\
4 & M4 & 70 & 30 & fume \& 2\% of Conplast SP430 admixture \\
5 & M5 & 60 & 40 & is added to cement weight \\
6 & M6 & 50 & 50 & \\
7 & M7 & 25 & 100 & \\
8 & M8 & 0 & & \\
\hline
\end{tabular}

TABLE 3: Compressive strength split tensile strength and flexural strength for mixing concrete.

\begin{tabular}{|c|c|c|c|c|c|c|}
\hline \multirow{2}{*}{ Sl. number } & \multirow{2}{*}{ Mix type } & \multicolumn{2}{|c|}{ Compressive strength (Mpa) } & \multicolumn{2}{|c|}{ Split tensile strength (Mpa) } & \multirow{2}{*}{$\begin{array}{l}\text { Flexural strength }(\mathrm{Mpa}) \\
28 \text { days }\end{array}$} \\
\hline & & 7 days & 28 days & 7 days & 28 days & \\
\hline 1 & M1 & 21.6 & 26.4 & 1.78 & 1.880 & 22.04 \\
\hline 2 & M2 & 22.41 & 27.8 & 1.828 & 2.107 & 23.81 \\
\hline 3 & M3 & 23.32 & 28.35 & 1.88 & 2.162 & 25.17 \\
\hline 4 & M4 & 23.97 & 29.31 & 1.91 & 2.230 & 26.90 \\
\hline 5 & M5 & 25.21 & 30.64 & 1.97 & 2.279 & 28.55 \\
\hline 6 & M6 & 24.32 & 29.67 & 1.85 & 2.229 & 26.65 \\
\hline 7 & M7 & 20.65 & 25.19 & 1.68 & 1.883 & 24.83 \\
\hline 8 & M8 & 18.49 & 23.24 & 1.62 & 1.810 & 22.80 \\
\hline
\end{tabular}

3.4. Split Tensile Strength. In order to find the split tensile test the different concrete mixes are casted in a standard cylinder of size diameters $150 \mathrm{~mm}$ and $300 \mathrm{~mm}$ in length. The casted concrete is demoulded after one day of casting and cured for 7 days and 28 days. The cured specimens were tested in CTM and the split tensile strength is obtained.

3.5. Flexural Strength Beams and Reinforcement Details. The size of the beam for finding the flexural strength is $1000 \times$ $150 \times 150 \mathrm{~mm}$. Totally 24 beams were casted and tested for their flexural strength.

From Figure 1 the load is at 1/3rd of the span and the distance of applying load is $300 \mathrm{~mm}$, the length is $150 \mathrm{~mm}$, and the breadth is $150 \mathrm{~mm}$ in the beam.

\section{ACO Algorithm}

The ACO algorithm represents one of the effective methods and possesses the significant features of the state transition regulation and the pheromone update technologies. A colony of ants is sent to locate the solutions in each and every iteration. Each ant performs each and every step strictly in accordance with the state transition regulation. When an ant completes a task, the local pheromone update is initiated on the chosen strength, which significantly scales down the probability for the other ants to select the identical strength continually and thus paves the way for diversity in the search. After every ant has built a perfect solution, the global pheromone update mechanism is initiated on the edges of the best-so-far solution with an eye on amplifying the appeal of the localities. The concrete materials like coarse aggregate (CA), fine aggregate (FA), cement, water, silica fume (SF), superplasticizer (SP), and quarry dust (QD) are assured in the mixing ratio and compressive strength, split tensile strength, flexural strength, and deflection are analyzed after applying the load in the ACO technique.

4.1. Flowchart. Figure 2 shows the flowchart of the ant colony optimization (ACO) which is explained below. The solutions are initialized in the flow and the fitness functions are computed. Then the probability transition is formed based on the function of pheromone updating and then the evaporation is performed. Finally the optimum value is predicted under the minimum error value.

4.2. Initialize the Parameters. Initialize the controlling parameters $\alpha_{i j}$ and $\beta_{i j}$ in the solution and transmit them to the fitness calculation:

$$
R_{i}=\left\{R_{0 j}, R_{1 j}, \ldots, R_{n j}\right\},
$$



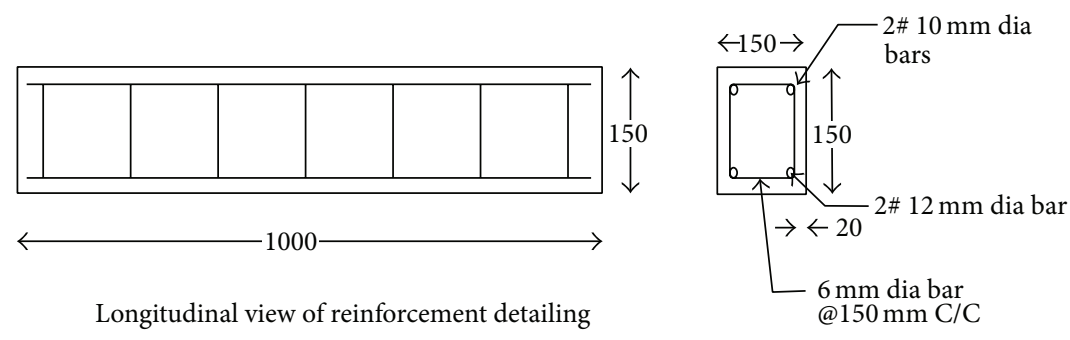

Cross section of beam

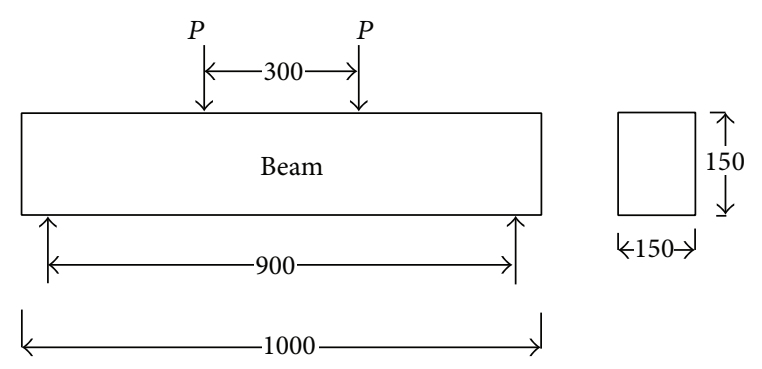

All dimensions are in $\mathrm{MM}$

Figure 1: Beam in deflection.

where $R_{i}$ defines an initial solution, $i \in[1,2, \ldots, 10]$, and $j \in$ $[1,2, \ldots, 160]$. Since $i$ th value is considered as the number of solution and $j$ th value is considered as the length of solution, then

$$
R_{j}=[(\text { No of hidden neuron } * \text { No of input data })+\text { No of hidden neuron }]
$$

where total input $=7$ and hidden neuron $(h)=20$.

Based on (2), the attained solution length is 160 and the solution range lies within $-10 \leq R_{i j} \leq 10$. According to the initial solution four outputs such as compressive strength (Mpa), split tensile strength (Mpa), flexural strength (Mpa), and deflection (in $\mathrm{mm}$ ) are evaluated.

4.3. Fitness Function. The Sigmoid function is derived as a function which is incorporated with the artificial neural network process to optimize the mathematical modeling. By optimizing $\alpha_{i j}$ and $\beta_{i j}$ in the function we can obtain the optimized mathematical modeling. The error value is attained as [original value - obtained value] in the mathematical modeling:

$$
\begin{aligned}
f_{i} & =\sum_{j=1}^{h} \alpha_{j} *\left[\frac{1}{1+\exp \left(-\sum_{i=1}^{N} R_{i} \beta_{i j}\right)}\right], \\
F_{i} & =\frac{\sqrt{(\text { original }- \text { obtained })^{2}}}{\text { No of input data }} .
\end{aligned}
$$

Equation (4) is considered for the fitness computation in the optimization. The error value is minimized in the fitness which is computed to predict the optimal solution by using the controlling parameters such as $\alpha_{i j}$ and $\beta_{i j}$. N indicates number of data. The outputs considered as the optimal solutions constitute compressive strength (Mpa), split tensile strength (Mpa), flexural strength (Mpa), and deflection (in $\mathrm{mm})$.

4.4. Probability Transition Matrix. At each and every configuration phase, ant $c$ applies a probabilistic action choice rule, known as the random proportional rule, to determine which location has to be visited next. Particularly, the probability with which ant $c$, currently at location $i$, prefers to go to location $j$ is detailed below:

$$
P_{i j}^{c}=\frac{\left(\tau_{i j}\right)^{\alpha}\left(\eta_{i j}\right)^{\beta}}{\sum\left(\tau_{i j}\right)^{\alpha}\left(\eta_{i j}\right)^{\beta}},
$$

where $\eta_{i j}=1 / d_{i j}$ represents a heuristic value and edges $(i, j)$ where $j$ is a location that the ant $c$ has not visited till now. By this probability regulation, the possibility of choosing a specific arc $(i, j)$ enhances the value of the linked pheromone trail $\tau_{i j}$ and of the heuristic data value $\eta_{i j}$ and the parameters $\alpha$ and $\beta$ organize the comparative significance of the pheromone versus the heuristic data, which is furnished by $\eta_{i j}$ (i.e., if $\alpha_{i j}=0$, the contiguous cities are further likely 


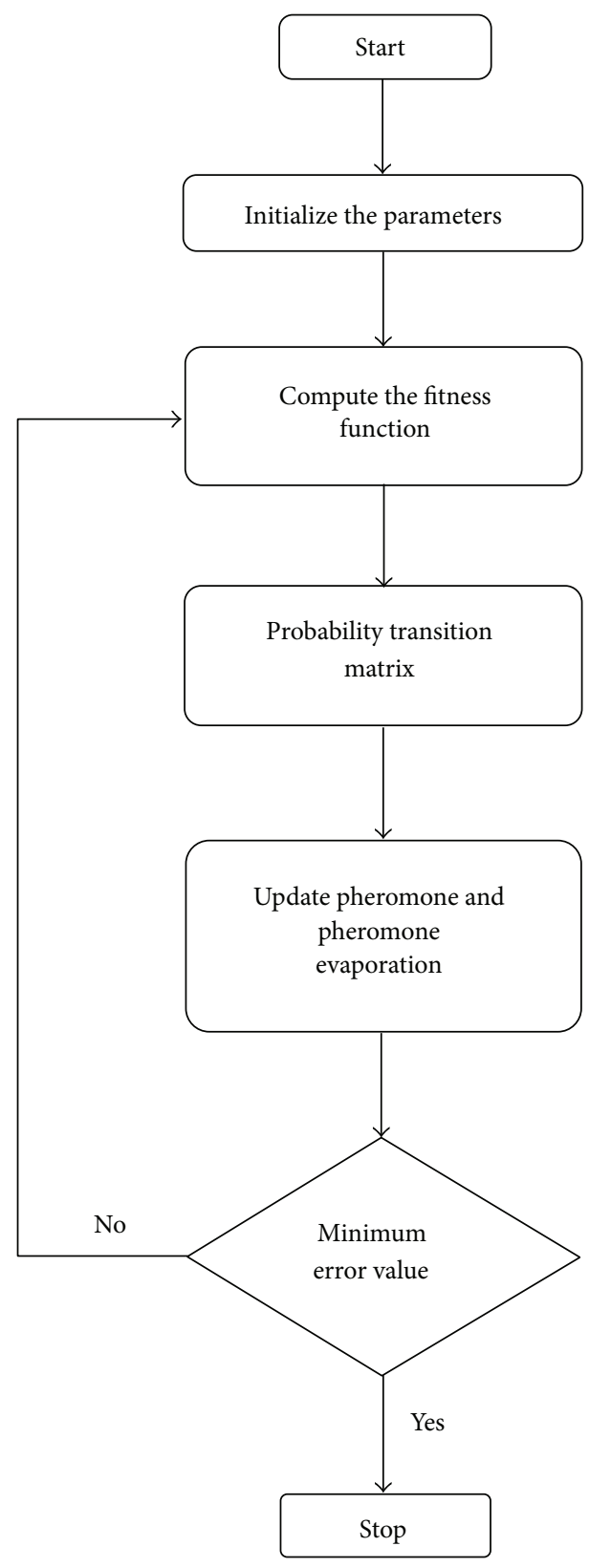

Figure 2: Flowchart for mathematical modeling with ant colony optimization.

to be chosen, while if $\beta_{i j}=0$, only pheromone amplification is functioning).

4.5. Update Pheromone and Evaporation Pheromone. The pheromone values are updated when all the $s$ ants have formed solutions after their iteration. The pheromone intensity linked with the edge joining locations $i$ and $j$ is updated below:

$$
\tau_{i j}=(1-\rho) * \tau_{i j}+\sum_{c=1}^{s} \Delta \tau_{i j}^{c}
$$

where $\rho$ is pheromone evaporation rate, $s$ is the number of ants, and $\Delta \tau_{i j}^{c}$ is the quantity of pheromone laid on edge $(i, j)$ by $c$ th ant. Consider

$$
\begin{aligned}
& \Delta \tau_{i j}^{c} \\
& = \begin{cases}\frac{Q}{L c} ; & \text { if ant } c \text { used connection }(i, j) \text { in its tour } \\
0 ; & \text { otherwise. }\end{cases}
\end{aligned}
$$

Equation (6) comprises two distinct components. The left segment enables the pheromone on all edges decay. The speed of this decay is represented by $\rho$, which is the evaporation constraint. The right segment enhances the pheromone on all the edges visited by ants. The amount of pheromone an ant $c$ deposits on an edge is indicated by $L c$ which represents the length of the tour generated by the related ant. In this manner, the enhancement of pheromone for an edge is clearly dependent on the number of ants that utilize this edge and on the excellence of the solutions located by those ants. The updating procedure of ACO technique is shown in above process. Finally the error is forecast until the minimization.

The fitness function is performed in the equations below:

$$
F_{i}=F_{1}, F_{2}, F_{3}, F_{4},
$$

where $F_{1}$ is compressive strength, $F_{2}$ is split tensile strength, $F_{3}$ is flexural strength, and $F_{4}$ is deflection.

The outputs considered as the optimal solutions like compressive strength $(\mathrm{Mpa})$ as $\left(F_{1}\right)$, split tensile strength (Mpa) as $\left(F_{2}\right)$, flexural strength (Mpa) as $\left(F_{3}\right)$, and deflection (in $\mathrm{mm}$ ) as $\left(F_{4}\right)$ are applied in the fitness function for predicting the optimal solution:

$$
\left.f_{i}=\sum_{j=1}^{h} \alpha_{j_{(\mathrm{opt})}} *\left[\frac{1}{1+\exp \left(-\sum_{i=1}^{N} R_{i} \beta_{i j}(\mathrm{opt})\right.}\right)\right] .
$$

From (9) the outputs $F_{2}, F_{3}, F_{4}$ are calculated and the optimal value is obtained.

\section{Result and Discussion}

The different inputs represent coarse aggregate (CA), fine aggregate (FA), cement, water, silica fume (SF), superplasticizer (SP), quarry dust (QD), load (KN), and ultimate load $(\mathrm{KN})$. The proposed mathematical modeling with the ant colony optimization is used to find the optimal solutions like compressive strength (Mpa), split tensile strength (Mpa), flexural strength (Mpa), and deflection (in $\mathrm{mm}$ ). During the optimization procedure, at the outset, the constraints such as the minimum cost and time reduction are assigned. The ant colony optimization is used with the mathematical modeling in the concrete mixing ratios and the strength is analyzed by applying the load in the concrete. In the real time experiment the cost required is high and the time is extended and to solve the problem the mathematical modeling is mentioned to optimize compressive strength (Mpa), split tensile strength (Mpa), flexural strength (Mpa), and deflection (in $\mathrm{mm}$ ). 


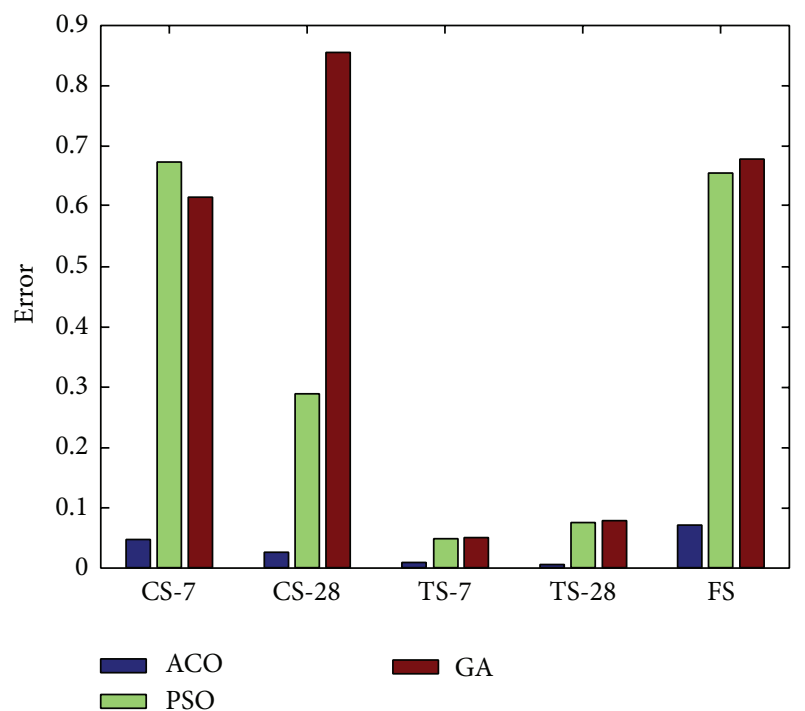

FIGURE 3: Error value graph.

5.1. Mathematical Modeling with Optimization Techniques. The mathematical modeling with PSO, GA, and ACO yields the minimum error value for finding the optimal equation with the optimal controlling parameters $\left(\alpha_{i j}\right.$ and $\left.\beta_{i j}\right)$. The error is minimum when the ACO algorithm is used compared with the other techniques such as the GA and PSO. Figure 3 shows the error graph for the mathematical modeling with genetic algorithm (GA), particle swarm optimization (PSO), and ant colony optimization (ACO) which are the optimization techniques used to find the error value of the mathematical modeling.

The error value is determined by using the difference between the predicted values and desired values and it gives the fitness of the mathematical modeling. In Figure 3 the error graph shows that the ant colony optimization algorithm minimizes the error value in the compressive strength (CS7) (CS-28), the split tensile strength (TS-7) (TS-28), and the flexural strength (FS) to 0.02967 when compared to other techniques like GA and PSO.

Figure 4 shows the deflection error when applying the load in a certain range and the minimization of error value is predicted by the ant colony optimization (ACO) compared to the GA and PSO. The load is taken as 10 to $90 \mathrm{KN}$ and the error value is zero. The prediction performance of the deflection is $94 \%$ in the mathematical modeling.

5.2. Experimental Results. The ACO algorithm offers the optimal solutions such as compressive strength (Mpa), split tensile strength (Mpa), flexural strength (Mpa), and deflection (in $\mathrm{mm}$ ).

Table 3 shows the compressive strength, the split tensile strength, and the flexural strength of concrete while mixing coarse aggregate (CA), fine aggregate (FA), cement, water, silica fume (SF) and $10 \%$ of each mixing ratio except M1, superplasticizer (SP) and 2\% of each mixing ratio except M1, and quarry dust (QD) in percentage like $10 \%, 20 \%$ up to $100 \%$

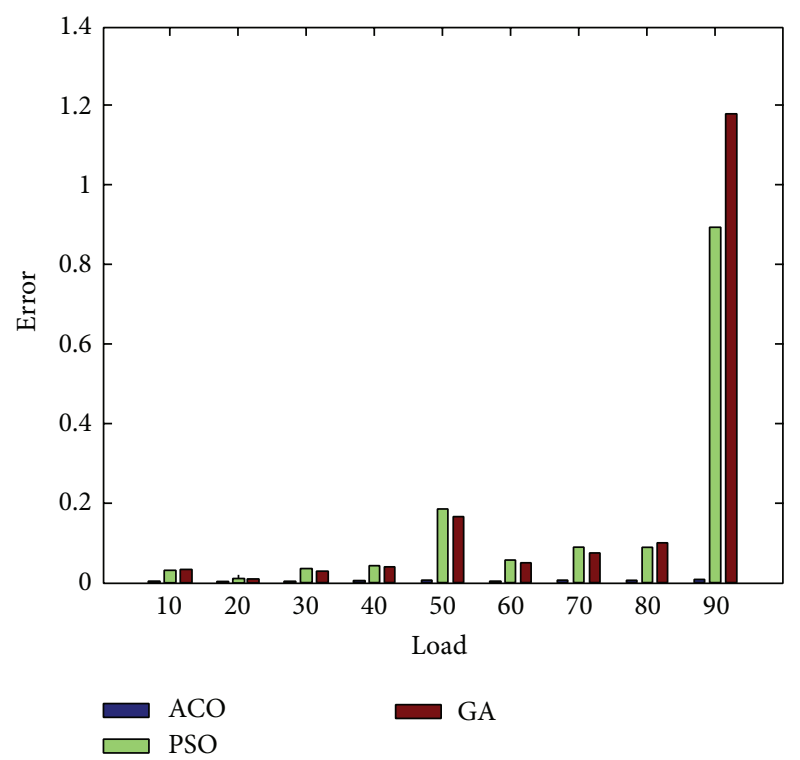

FIGURE 4: Error graph of deflection.

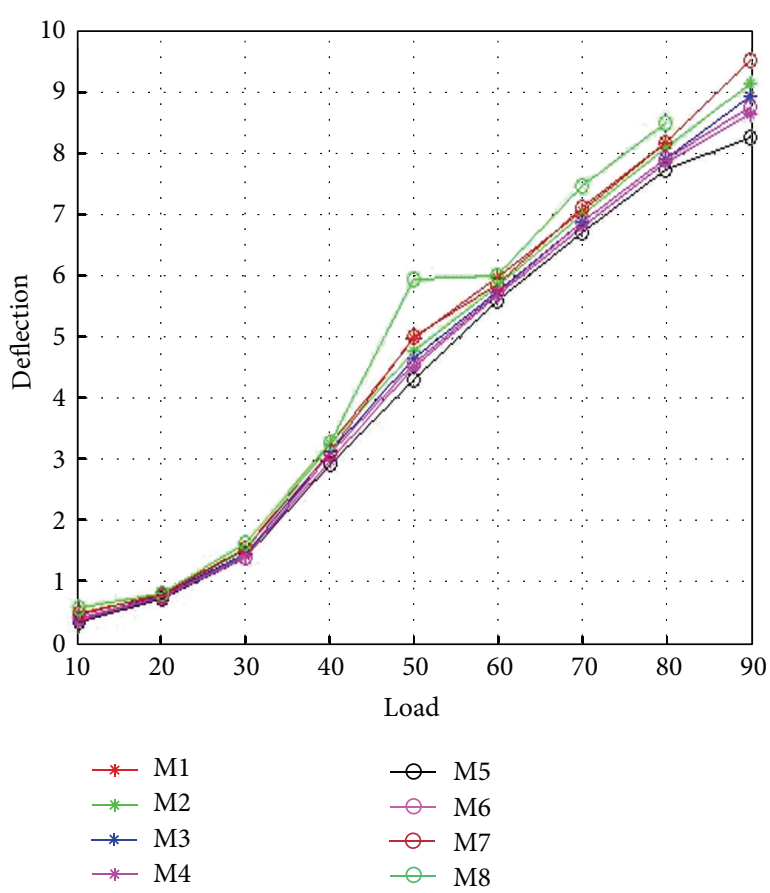

Figure 5: Load versus deflection.

are added except M1 mixing ratio for 7 days and 28 days. In this process the ACO is used in the mathematical modeling to predict the optimal solutions.

Figure 5 shows the deflection in the center of the concrete beam as $\mathrm{M} 1$ to $\mathrm{M} 8$ mixing ratio by using the $\mathrm{ACI}$ method of mix design with the lightweight concrete and replacement of the quarry dust. The load is applied at the $1 / 3$ rd of the span like $10 \mathrm{KN}, 20 \mathrm{KN}$ up to $100 \mathrm{KN}$ and the deflection is calculated by the measuring instruments. 
TABLE 4: Compressive strength split tensile strength and flexural strength for mixing concrete.

\begin{tabular}{lcccccc}
\hline \multirow{2}{*}{ Sl. number } & \multirow{2}{*}{ Mix type } & \multicolumn{2}{c}{ Compressive strength (Mpa) } & \multicolumn{2}{c}{ Split tensile strength (Mpa) } & \multicolumn{2}{c}{ Flexural strength (Mpa) } \\
& & 7 days & 28 days & 7 days & 28 days & 28 days \\
\hline 1 & M1 & 22.3634 & 26.4 & 1.780148 & 1.983401 & 23.98486 \\
2 & M2 & 22.3534 & 27.79988 & 1.831565 & 2.149852 & 25.16909 \\
3 & M3 & 23.39843 & 29.0571 & 1.83313 & 2.149852 & 26.93635 \\
4 & M4 & 23.39843 & 29.31015 & 1.833131 & 2.224513 & 28.55261 \\
5 & M5 & 23.38843 & 30.64 & 1.833131 & 2.279675 & 26.63621 \\
7 & M6 & 26.06786 & 29.67506 & 1.833131 & 2.224513 & 24.75354 \\
8 & M7 & 17.43668 & 25.1898 & 1.709717 & 1.87364 & 22.79477 \\
\hline
\end{tabular}
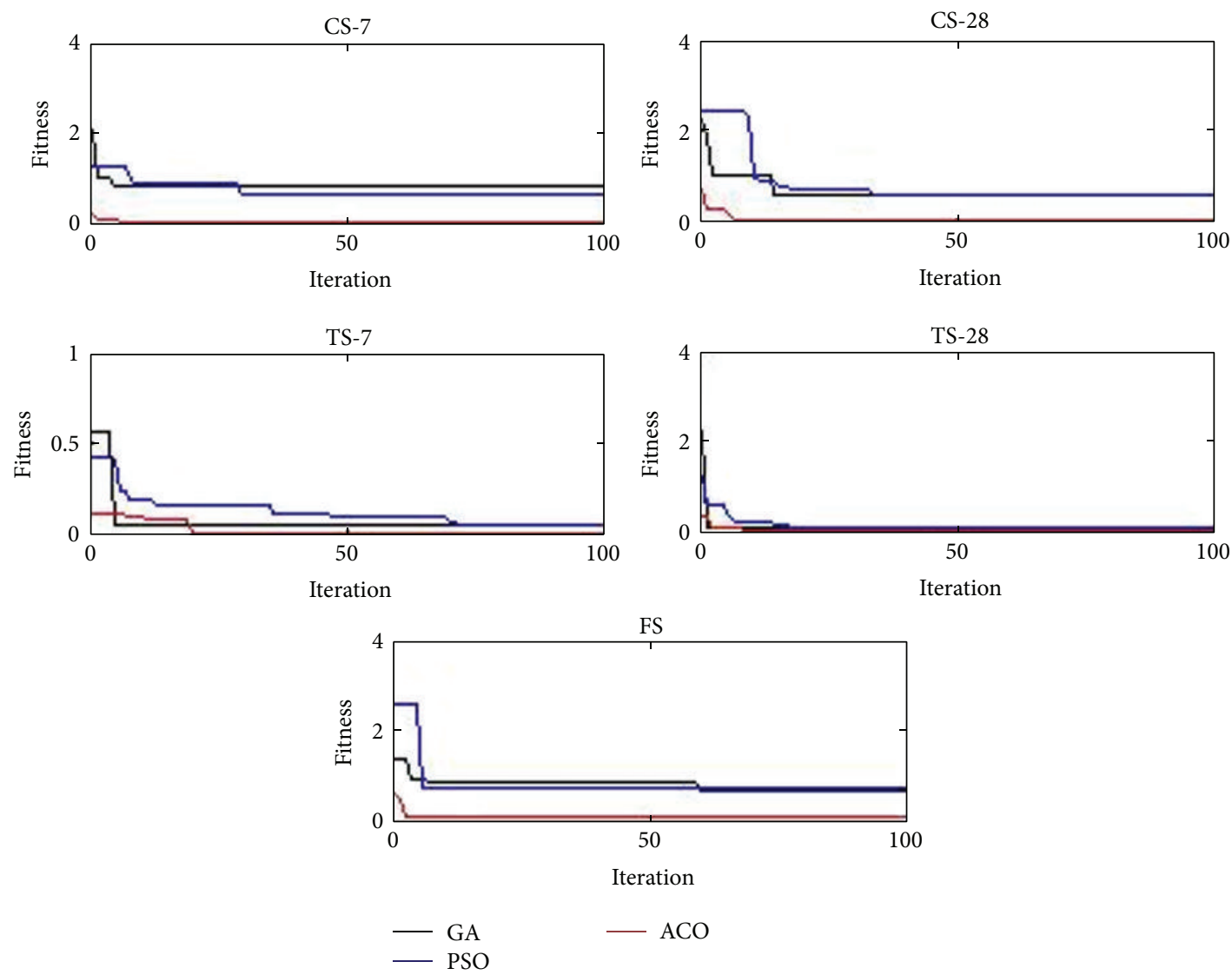

FIGURE 6: Convergence graph.

5.3. Optimal Solutions of the ACO. In Table 4 the optimal solutions for the different concrete mixings are shown. From the mathematical modeling of the compressive strength, the flexural strength, and the split tensile strength the optimal values are obtained from the ACO algorithm. Based on the mixing coarse aggregate (CA), fine aggregate (FA), cement, water, silica fume (SF) and $10 \%$ of each mixing ratio except $\mathrm{M} 1$, and superplasticizer (SP) and $2 \%$ of each mixing ratio except the optimal solutions are obtained. In 7-day testing of M1 mixing the compressive strength is 22.363 and compared to the 28 days the variation is $4.23 \%$. Similarly in the other days also the optimal strength is attained.
5.4. Convergence Graphs. In Figure 6, the convergence graph is plotted between the iteration and fitness estimations of the various strategies, such as GA, PSO, and ACO. The graph shows that the ACO procedure gives the greatest fitness using the least possible iteration. Through the graph, the ACO strategy takes the minimum iteration for providing the ideal result and it receives the primary greatest estimation of the fitness. Subsequently, in the compressive strength, the value is minimized in the ACO technique and the ultimate load is utilized to predict the optimal solution and in the same process the split tensile strength and flexural strength are presented. In the convergence the iteration of compressive 

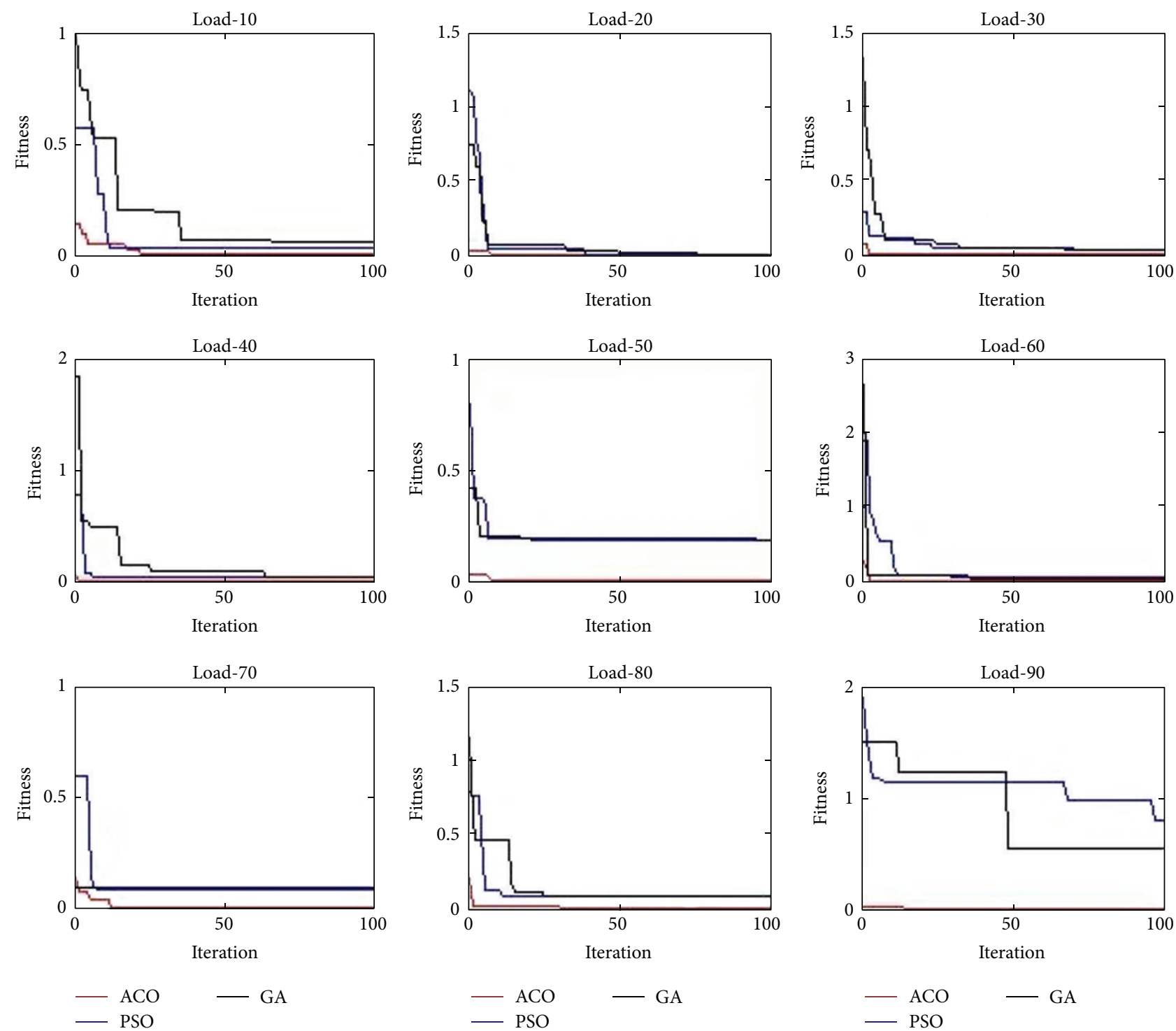

FIGURE 7: Convergence graph of deflection.

strength is for 7 days and 28 days and the fitness variation is 0 to 4 and then in split tensile strength for 7 days from 0 to 100 iterations shows from 0 to 1 fitness variation and for 28 days it is varied from 0 to 4 ; then at the end the flexural strength for 28 days shows from 0 to 4 fitness variations in convergence.

Figure 7 shows that in the deflection convergence the fitness and iteration are estimated in the graph by applying load at the $1 / 3$ rd of the span. The deflection is formed and the performance is calculated under $10 \mathrm{KN}$ to $90 \mathrm{KN}$ load in each iteration. The ACO is the least in the iteration compared to the other techniques such as the genetic algorithm (GA) and particle swarm optimization (PSO). In $10 \mathrm{KN}$ load the fitness is varied from 0 to 1 , in $20 \mathrm{KN}$ load the fitness is varied from 0 to 1.5 , in $30 \mathrm{KN}$ load the fitness is varied from 0 to 1.5 , in $40 \mathrm{KN}$ load the fitness is varied from 0 to 2 , in $50 \mathrm{KN}$ load the fitness is varied from 0 to 1 , in $60 \mathrm{KN}$ load the fitness is varied from 0 to 3 , in $70 \mathrm{KN}$ load the fitness is varied from 0 to 1 , in
$80 \mathrm{KN}$ load the fitness is varied from 0 to 1.5 , and in $90 \mathrm{KN}$ load the fitness is varied from 0 to 2 .

5.5. Prediction of Outputs. Figures 8, 9, and 10 and Table 5 show the variation in the actual and predicted results of 7 days and 28 days of the mixes M1 to M8 using the ACO technique for various parameters such as the compressive strength, the split tensile strength, and the flexural strength. The training and testing values are deployed to ascertain the objective functions of the mathematical modeling. The same procedure is performed for 7 days and 28 days, respectively. In the case of the flexural strength, the strength is varied up to 29 , and here the predicted value is high whereas the actual value is low. The experimental results are compared to the predicted results and the error has a minimum value. By using the mathematical modeling with the ACO technique the prediction is achieved. 
TABLE 5: Comparison of actual and predicted results for various parameters.

\begin{tabular}{|c|c|c|c|c|}
\hline Number of data & Parameter/test & Curing period & Variation & High-level variation mix \\
\hline \multirow{2}{*}{ M1 to M8 } & \multirow{2}{*}{ Compressive strength } & 7 days & 2 & \multirow{2}{*}{ M5 } \\
\hline & & 28 days & 2.5 & \\
\hline \multirow{2}{*}{ M1 to M8 } & \multirow{2}{*}{ Split tensile strength } & 7 days & 1.7 & \multirow{2}{*}{ M5 } \\
\hline & & 28 days & 1.8 & \\
\hline M1 to M8 & Flexural strength & 28 days & 2.2 & M5 \\
\hline
\end{tabular}
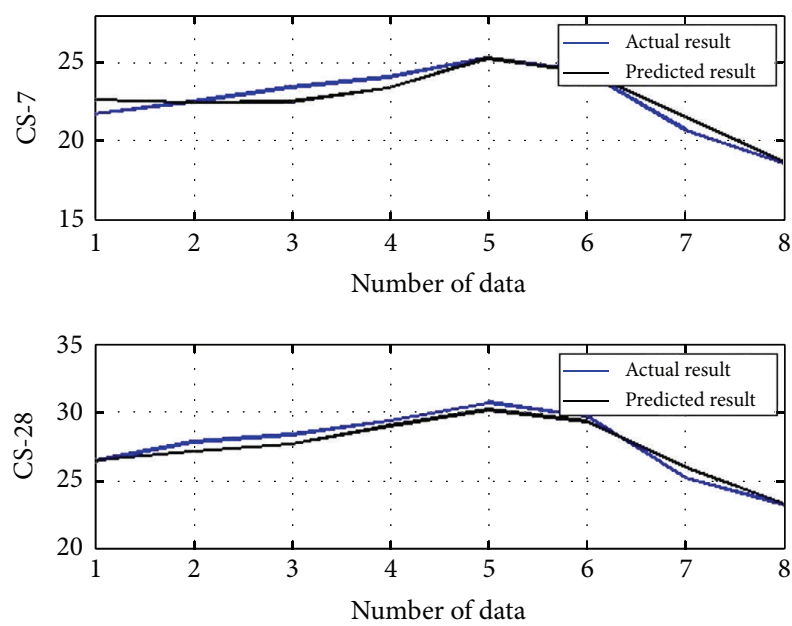

FIGURE 8: Prediction of compressive strength.
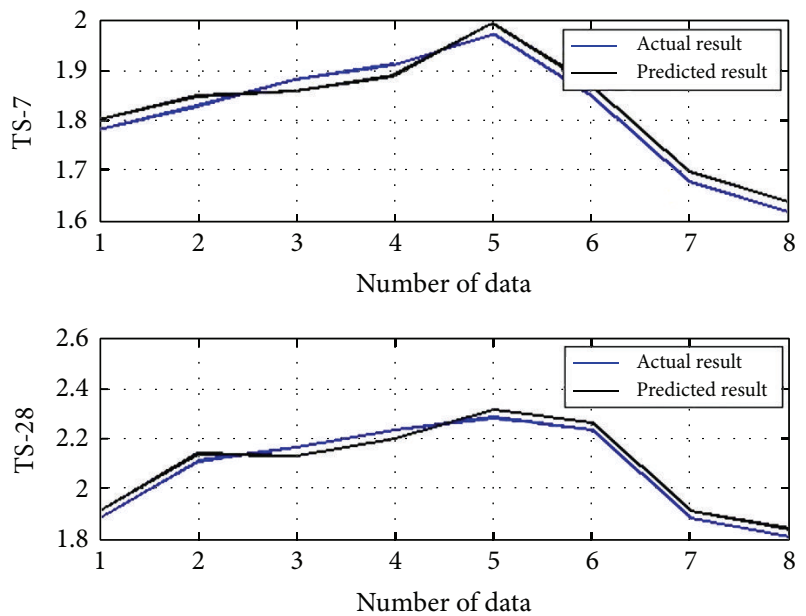

FIGURE 9: Prediction of split tensile strength.

Figure 11 and Table 6 show the deflections by applying the $1 / 3 \mathrm{rd}$ span of the beam. The lightweight concrete with the silica fume (SF), the superplasticizer (SP), and the quarry dust (QD) is added to the mix design, and then the beam is cured for 28 days, respectively, and the specimens are used for finding various parameters such as the compressive strength, the split tensile strength, and the flexural strength. Finally the load is applied at the 1/3rd of the span in the beam and the deflection is specified, and then with the help of

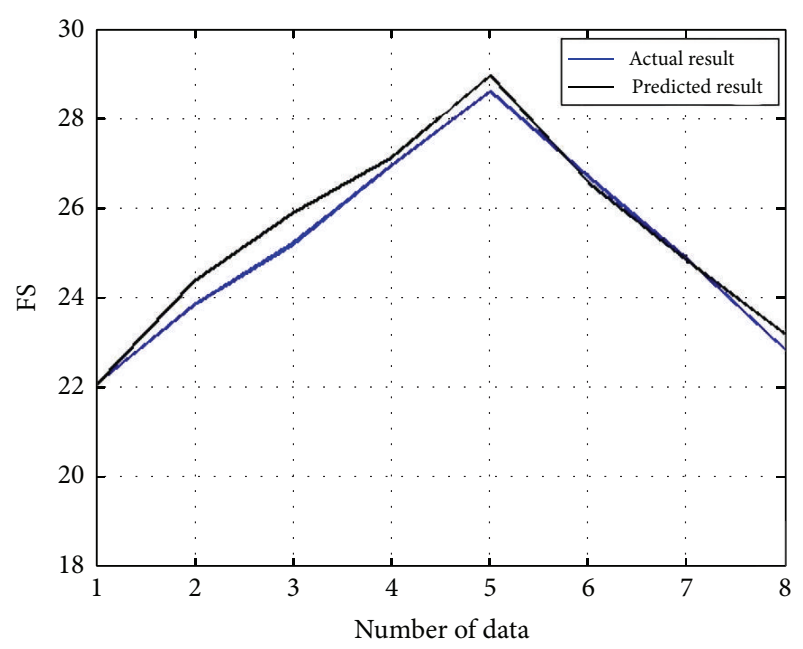

FIgURE 10: Prediction of flexural strength.

TABLE 6: Variation on actual and predicted values of deflection in flexural strength test.

\begin{tabular}{lcc}
\hline Load & Number of data & Variation: actual versus predicted \\
\hline 10 & M1 to M8 & 0 to 1 \\
20 & M1 to M8 & 0.7 to 0.9 \\
30 & M1 to M8 & 0 to 4 \\
40 & M1 to M8 & 0 to 10 \\
50 & M1 to M8 & 0 to 10 \\
60 & M1 to M8 & 0 to 10 \\
70 & M1 to M8 & 0 to 10 \\
80 & M1 to M8 & 0 to 10 \\
90 & M1 to M8 & -20 to 20 \\
\hline
\end{tabular}

the mathematical modeling in the ACO technique, the prediction is analyzed and performed.

\section{Conclusion}

The offered numerical modeling with the ant colony optimization strategy is executed for various parameters such as compressive strength (Mpa), split tensile strength (Mpa), flexural strength (Mpa), and deflection (in $\mathrm{mm}$ ). The inputs like coarse aggregate (CA), fine aggregate (FA), cement, water, silica fume (SF), superplasticizer (SP), quarry dust (QD), load $(\mathrm{KN})$, and ultimate load $(\mathrm{KN})$ are involved to predict the minimum values. In each output the mathematical modeling with the ant colony optimization is performed and the results 

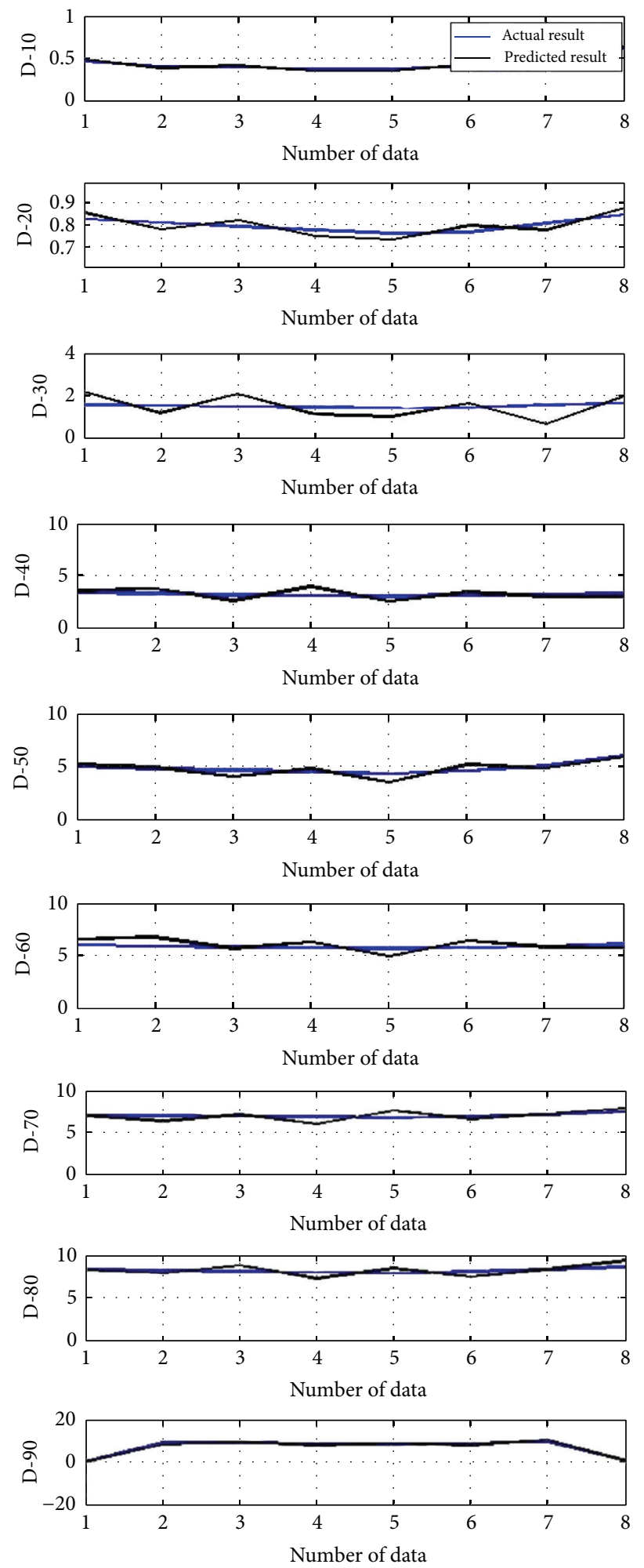

FIGURE 11: Prediction of load versus deflection.

are shown. According to the mathematical modeling the fitness is analyzed for various parameters such as compressive strength, split tensile strength, flexural strength, and deflection. The mathematical modeling with the optimization is utilized to minimize the cost and to save the time in the future experiments. The performance obtained in the ACO for various parameters such as compressive strength, split tensile strength, flexural strength, and deflection is 
$91 \%, 98 \%, 87 \%$, and $94 \%$ of predicted values, respectively, in the mathematical modeling. It is worth mentioning that the entire procedure gets well implemented in the working platform of the MATLAB software. It is also revealed from the experimental data that the mix proportion of M5 gives good results in partial replacement of the quarry dust in the fine aggregate in the analysis of the compressive strength, the split tensile test, and the flexural properties.

\section{Conflict of Interests}

The authors declare that there is no conflict of interests regarding the publication of this paper.

\section{References}

[1] V. Patel and N. Shah, "A survey of high performance concrete developments in civil engineering field," Journal of Civil Engineering, vol. 3, no. 2, pp. 69-79, 2013.

[2] K. W. Hoe and M. Ramli, "Rational mix design approach for high strength concrete using sand with very high fineness modulus," American Journal of Applied Sciences, vol. 7, no. 12, pp. 1562-1568, 2010.

[3] M. M. Al Bakri, H. Mohammed, H. Kamarudin, K. Niza, and Y. Zarina, "Review on fly ash-based geopolymer concrete without Portland Cement," Journal of Engineering and Technology Research, vol. 3, no. 1, pp. 1-4, 2011.

[4] H. K. Kim, J. H. Jeon, and H. K. Lee, "Workability, and mechanical, acoustic and thermal properties of lightweight aggregate concrete with a high volume of entrained air," Construction and Building Materials, vol. 29, pp. 193-200, 2012.

[5] A. Ben Fraj, M. Kismi, and P. Mounanga, "Valorization of coarse rigid polyurethane foam waste in lightweight aggregate concrete," Construction and Building Materials, vol. 24, no. 6, pp. 1069-1077, 2010.

[6] S. O. Franklin, "Modelling of the compressive and tensile strength relationship of concrete in studies on the punching phenomenon in prestressed flat slabs," Journal of Applied Sciences Research, vol. 6, no. 3, pp. 205-211, 2010.

[7] P. Ramadoss, "Modeling for the evaluation of strength and toughness of high-performance fiber reinforced concrete," Journal of Engineering Science and Technology, vol. 7, no. 3, pp. 280291, 2012.

[8] P. Appukutty and R. Murugesan, "Substitution of quarry dust to sand for mortar in brick masonry works," International Journal on Design and Manufacturing Technologies, vol. 3, no. 1, pp. 5963, 2009.

[9] P. P. Nanda, A. K. Das, and N. C. Moharana, "Stone crusher dust as a fine aggregate in concrete for paving blocks," Journal of Civil and Structural Engineering, vol. 1, no. 3, pp. 613-620, 2010.

[10] C. Sukesh, K. B. Krishna, P. Sri Lakshmi Sai Teja, and S. Kanakambara Rao, "Partial replacement of sand with quarry dust in concrete," International Journal of Innovative Technology and Exploring Engineering, vol. 2, no. 6, pp. 254-258, 2013.

[11] J. O. Ukpata, M. E. Ephraim, and G. A. Akeke, "Compressive strength of concrete using lateritic sand and quarry dust as fine aggregate," Journal of Engineering and Applied Sciences, vol. 7, no. 1, pp. 81-92, 2012.

[12] J. O. Ukpata and M. E. Ephraim, "Flexural and tensile strength properties of concrete using lateritic sand and quarry dust as fine aggregate," Journal of Engineering and Applied Sciences, vol. 7, no. 3, pp. 324-331, 2012.

[13] A. Jayaraman, V. Senthilkumar, and M. Saravanan, "Compressive and tensile strength of concrete using lateritic sand and lime stone filler as fine aggregate," Journal of Research in Engineering and Technology, vol. 3, no. 1, pp. 79-84, 2014.

[14] R. Ilangovana, N. Mahendrana, and K. Nagamanib, "Strength and durability properties of concrete containing quarry rock dust as fine aggregate," Journal of Engineering and Applied Sciences, vol. 3, no. 5, pp. 20-26, 2008.

[15] M. S. Hameed and A. S. S. Sekar, "Properties of green concrete containing quarry rock dust and marble sludge powder as fine aggregate," Journal of Engineering and Applied Sciences, vol. 4, no. 4, pp. 83-89, 2009.

[16] A. U. Abubakar and K. S. Baharudin, "Compressive strength of high volume coal bottom ash utilization as fine aggregate in fly ash-cement blended concrete," Journal of Engineering \& Technology Sciences, vol. 1, no. 4, pp. 226-239, 2013.

[17] A. Sivakumar and P. Gomathi, "Pelletized fly ash lightweight aggregate concrete: a promising material," Journal of Civil Engineering and Construction Technology, vol. 3, no. 2, pp. 4248, 2012.

[18] A. Kabir, M. Hasan, and Md. K. Miah, "Strength prediction model for concrete," Journal of Civil Engineering, vol. 2, no. 1, pp. 14-19, 2013.

[19] M. R. Afify and N. M. Soliman, "Feasibility of using lightweight artificial coarse aggregates in the manufacture of R. C. elements," International Journal of Engineering and Advanced Technology, vol. 3, no. 2, pp. 290-306, 2013.

[20] M. Devi, "Performance evaluations of calcium nitrite on steel rebar corrosion in quarry dust concrete," Journal of Engineering and Science, vol. 2, no. 10, pp. 23-27, 2013.

[21] L. Nagpal, A. Dewangan, S. Dhiman, and S. Kumar, "Evaluation of strength characteristics of concrete using crushed stone dust as fine aggregate," Journal of Innovative Technology and Exploring Engineering, vol. 2, no. 6, pp. 102-104, 2013.

[22] T. Subbulakshmi and B. Vidivelli, "Mechanical properties of high performance concrete in corporating with quarry wastes," Journal of Engineering and Advanced Technology, vol. 3, no. 6, pp. 231-236, 2014. 

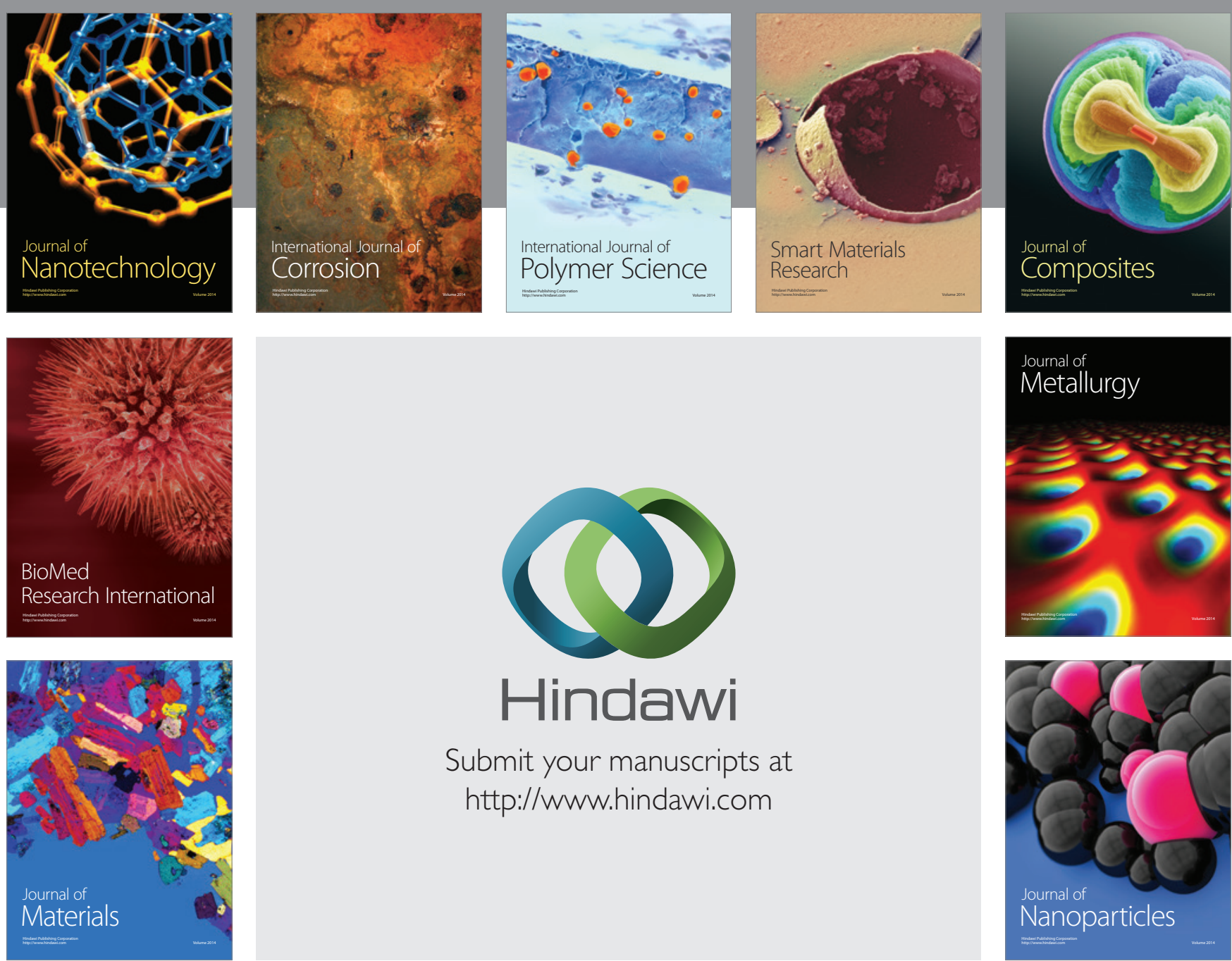

\section{Hindawi}

Submit your manuscripts at

http://www.hindawi.com

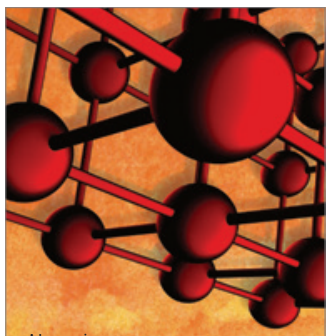

Materials Science and Engineering
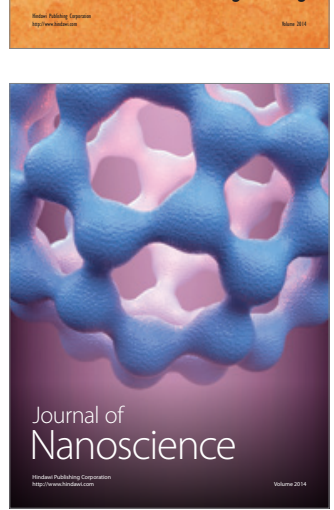
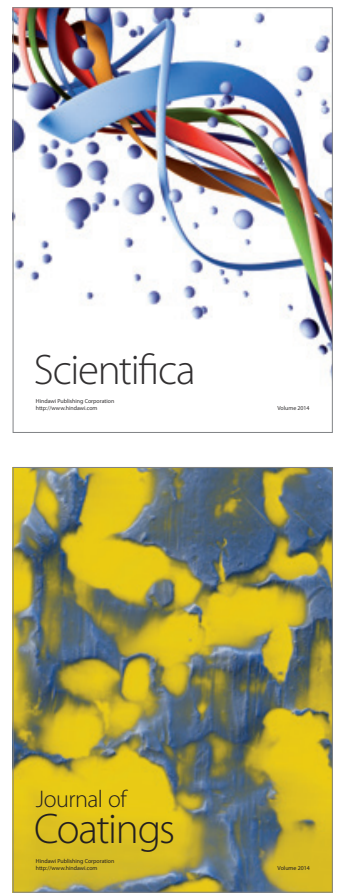
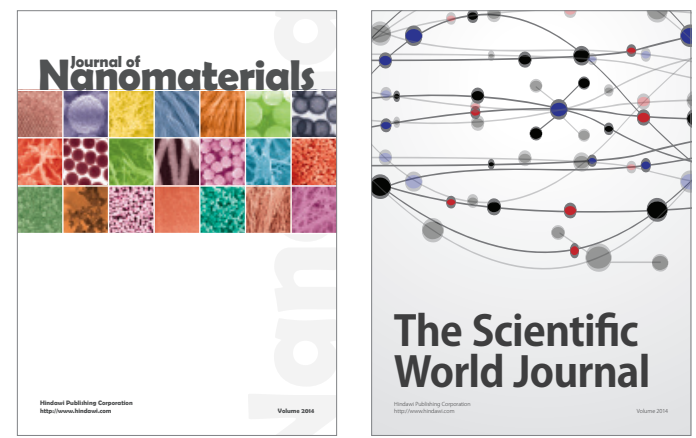

The Scientific World Journal
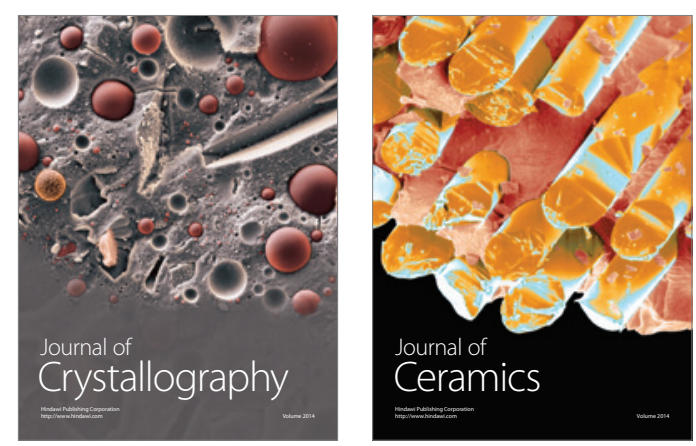
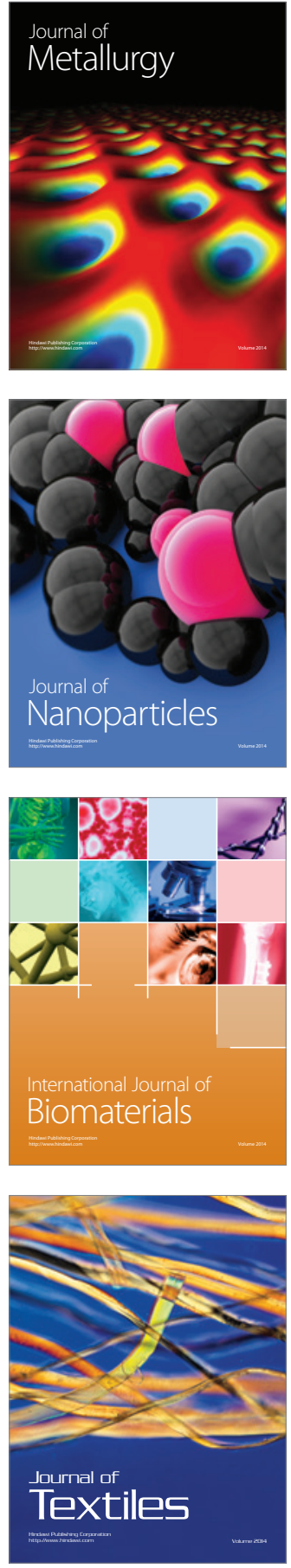